\title{
VISITAÇÃO DOMICILIÁRIA EM CONTEXTO COVID19: NARRATIVA
}

\author{
VISITA A DOMICILIO EN EL CONTEXTO COVID19: NARRACIÓN
}

HOME VISITATION IN COVID19 CONTEXT: NARRATIVE

DOI 10.33194/rper.2020.v3.s2.10.5831 | Submetido 26/09/2020 | Aprovado 17/11/2020

\author{
Rui Pedro Silva ${ }^{1}$ \\ 1 - ACES Maia/Valongo
}

\section{RESUMO}

O contexto COVID19 acarretou alterações significativas no modo de funcionamento das unidades prestadoras de cuidados de saúde, com a visitação domiciliária a sofrer um impacto particularmente relevante. Este artigo descreve, com perspetiva em primeira pessoa, parte de um dia de trabalho de um enfermeiro que presta cuidados em regime de visitação domiciliária em contexto COVID19. Ao fazê-lo, aborda os procedimentos, pensamentos e sentimentos do enfermeiro, evidenciando a experiência real de prestar cuidados ao domicílio durante a pandemia.

Palavras-chave: COVID19; EPI; visitação domiciliária

\section{RESUMEN}

El contexto de COVID19 provocó cambios significativos en la forma de operar de las unidades de salud, teniendo la visita domiciliaria un impacto particularmente relevante. Este artículo describe, desde una perspectiva en primera persona, parte de la jornada laboral de una enfermera que brinda atención de visitas domiciliarias en un contexto de COVID19. Al hacerlo, aborda los procedimientos, pensamientos y sentimientos de la enfermera, destacando la experiencia real de brindar atención domiciliaria durante la pandemia.

Palabras clave: COVID19; EPP; visitas domiciliarias

\section{ABSTRACT}

The COVID19 context led to significant changes in the way health care units operate, with home visitation having a particularly relevant impact. This article describes, from a first-person perspective, part of a working day for a nurse who provides home visitation care in a COVID context19. In doing so, it addresses the nurse's procedures, thoughts and feelings, highlighting the real experience of providing home care during the pandemic.

Keywords: COVID19; EPP; homecare

Estaciono o carro no parque do Centro de Saúde. São 12:50 de mais um dia de abril e estou a iniciar mais um turno. Saio do carro e dirijo-me à porta de entrada do centro de saúde onde 5 pessoas aguardam cá fora a sua vez de entrar. Ao fim de alguns passos apercebo-me que me esqueci de colocar a máscara e refaço o caminho até ao carro; ainda não é obrigatório o uso de máscara no exterior, mas já o é no interior das instalações. Volto a dirigir-me até às portas automáticas, entro e cumprimento a colega que está a fazer triagem no hall do edifício; um pouco mais à frente o segurança levanta a mão em forma de saudação e eu retribuo o gesto. Ao passar por ele recordo os apertos de mão que trocávamos diariamente e que são agora proibitivos.

Chego ao pontógrafo e direciono o dedo para o leitor envidraçado. Enquanto o faço, questiono-me involuntariamente quantas pessoas já lá colocaram o seu dedo hoje e se alguma delas lá depositou o vírus que transformou a nossa vida. Após um pequeno compasso de espera, aplico o meu dedo e, de imediato, desinfeto as mãos com a SABA (Solução Antissética de Base Alcoólica) estrategicamente colocado ao lado do pontógrafo enquanto olho, pela enésima vez, para as instruções de higienização das mãos.

Ainda com as mãos frias pela passagem do ar na pele húmida, vou para o meu posto de trabalho não sem antes cumprimentar todos os que já lá estão. Controlo o impulso de me sentar na cadeira ao ver que o teclado não está como o deixei no dia anterior; imediatamente, emergem-me hipóteses: "Será que alguém usou o meu posto de trabalho? Será que foi simplesmente a $D$. A... a limpar? Será que já estou a ficar paranóico com isto e fui eu que deixei o teclado assim?..." Para ficar em paz comigo mesmo, desinfeto o meu posto de trabalho, sento-me na cadeira e vejo o plano para o dia: 5 domicílios...

Reclino-me na cadeira, fito o teto e praguejo para mim próprio: " 5 domicílios... Onde vou arranjar 5 EPIs* para os fazer?...". Levanto-me e dirijo-me para o armazém, na esperança de já ter chegado uma nova remessa de EPIs higienizados; ao ver o saco à entrada do armazém,

* Equipamentos de Proteção Individual 
solto um "Porreiro!!!...", como se fosse um menino a olhar para uma prenda de Natal reciclada, mas que é tudo o que ele queria ter.

Abro o saco, olho para o procedimento de gestão de EPIs afixado na parede e começo a organizar o material para a realização dos domicílios: um saco por domicílio e em cada saco uma viseira, uma cogula, uma bata e um par de cobre-botas; a ordenação é importante para respeitar, por ordem inversa, a ordem de colocação dos EPIs. Junto os 6 sacos num saco maior (faço sempre um saco extra caso surja algum domicílio não programado) e olho para as prateleiras onde se encontra armazenado o material clínico.

Revejo mentalmente os procedimentos que vou realizar e localizo o material correspondente, o qual é individualizado por domicílio: aponto numa folha o material que retirei para posteriormente registar no sistema informático, sob pena de não haver reposição do mesmo. Vou já a sair do armazém quando penso: " $E$ se a algália do Sr. M... estiver de novo com muito sedimento? É melhor levar material para realgaliar". Estou a terminar de compilar mais um pequeno saco de material e penso: "E se a $D$. E... precisar que se faça hoje a troca da colostomia? É melhor levar também material..."; e mais um pequeno saco se junta aos demais. Ao sair do armazém volto a contemplar o seu interior no intuito de confirmar que não falhei na previsão do inesperado, pois não terei acesso ao material se me deparar com essas situações em casa dos utentes.

O trajeto do armazém até à viatura é acompanhado de um percurso mental da localização dos 5 domicílios e da melhor organização da sua ordem. "Bem, hoje não tenho nenhum caso de COVID19 positivo, por isso posso deixar o Sr. P... para último, e posso começar já por Sobrado, ficam os de mais longe feitos". Chego à viatura e monto os recipientes na mala, num sistema improvisado de abertura automática das tampas; a satisfação de ver o improviso funcionar (qual episódio de MacGyver) contrasta com a frustração de ter de recorrer ao improviso para obter os recursos que deviam estar disponíveis por defeito. Por último, verifico os recipientes de SABA e desinfetante e assumo-me pronto para sair; olho para o relógio da viatura e apercebo-me que meia hora já passou com todo este ritual...

Aciono o portão da garagem, cujo som metálico é interrompido pelo vibrar do meu telemóvel: "É a filha do Sr. A..., vai estar com dores...", comento comigo próprio. E não falho na previsão. Sendo um utente em fim de vida, com dor associada a múltiplas lesões de etiologia isquémica, é pertinente priorizar esse domicílio. Após dar indicação à filha do utente para aplicar de imediato o spray nasal analgésico, ajusto a ordem dos domicílios e dirijo-me a casa do utente.

Estaciono a viatura a cerca de 30 metros da porta do utente, num espaço exíguo onde espremi a viatura. Antes de sair, organizo mentalmente o que vou fazer: "Bem, é um prédio, por isso uso os dois pares de luvas para não correr o risco de contaminar o interior do apartamento depois de tocar nas superfícies externas; tenho de levar luvas adicionais porque são 4 feridas no total; é melhor usar o saco que tem a viseira da tira branca porque é a que embacia menos; vou colocar o telemóvel no bolso direito caso necessite de pegar nele para fotografar as feridas e enviar para a equipa de paliativos...".

Saio da viatura, regozijo-me por não estar a chover (curioso como se dá valor a pequenas coisas quando deparados com grandes males...) e equipo-me perante mirones curiosos nas janelas dos prédios circundantes. Já com aparência de astronauta e com um saco de material clínico na mão, vejo uma senhora apressada a atravessar para o outro lado da rua para não se cruzar comigo, enquanto me dirige um "boa tarde" sorridente, como se a se desculpar pelo medo.

Ao chegar ao prédio, toco na campainha com a mão dominante (tento seguir mentalmente o procedimento); a porta abre-se e dirijo-me ao apartamento do utente. Assim que entro no apartamento, retiro a luva da mão dominante para evitar contaminar o interior do apartamento com vírus provindo do exterior, enquanto penso: "Nunca mais esclarecem se as superfícies são efetivamente meios de propagação do vírus... espero bem que isto se venha a revelar um exagero...".

Já com a viseira a lançar uma névoa na minha visão, fruto dos três andares que subi pelas escadas e de mais uma vez me ter esquecido de lhe passar sabão, chego junto ao utente e cumprimento-o apesar de não ter dele uma resposta verbal; embora a norma da DGS indique que o utente deva estar com máscara, a experiência revelou que isso the trazia desconforto adicional, pelo que não peço para the ser colocada. Pergunto à filha como ele tem estado e ela confirma que o desconforto tem sido crescente; "Ok, vou abordar isso com a equipa de paliativos", digo-lhe enquanto pouso o saco do material no pequeno espaço livre na mesa de cabeceira. Normalmente faria o telefonema na própria altura e em presença do utente, mas o contexto pandémico impede quase por completo a utilização do telemóvel durante a realização do domicílio.

Peço ajuda à filha para posicionar o utente; enquanto o posicionamos, apercebo-me que tenho a porção distal das pernas a bater na grade descida da cama; penso: " $A$ bata que estou a usar não é das mais compridas... e as proteções de pés são curtas... já estou a tocar com a farda na grade de certeza... lá se vai a proteção de contacto...". Tento não me distrair com a preocupação e paro um pouco antes de remover os pensos. "Ok, tenho saco do lixo já pronto? Tenho compressas abertas caso escorra fluído das feridas? Tenho o Prontosan ${ }^{\circledR} a$ postos? Tenho luvas suficientes?" Antes do contexto pandémico era usual levar o "saco dos domicílios", um saco de dimensões consideráveis e que estava apetrechado com material extra; neste momento, só podemos contar com o que levamos no pequeno saco branco e não temos acesso a mais material enquanto estamos no domicílio. Após a checklist mental, prossigo com o tratamento das feridas.

Após remoção dos pensos e aplicação da solução de limpeza, debato-me com um lugar comum: quero avaliar corretamente as feridas mas uma catarata de vapor de água impede-me de ter uma visão adequada; 
olho por cima os óculos, espreito por debaixo da viseira, puxo o candeeiro da mesa de cabeceira... inspiro profundamente na tentativa de esconder a irritação da frustração por não ter a qualidade de visão necessária para tomar uma decisão com propriedade... e a expiração profunda que se segue volta a lançar uma névoa à minha frente. Ainda assim, consegui ver o que pretendia ver e ajusto o tratamento. Dado estar já com escassez de luvas ("espero bem que venham hoje mais luvas", penso), opto por não fotografar as feridas porque isso ia implicar a utilização de um par adicional.

Após terminar a realização dos tratamentos, e de tentar ignorar uma comichão irritante no nariz e à qual não consigo aceder devido à máscara, questiono a cuidadora se tem feito levante do utente para o cadeirão. "Hoje não quis fazer porque tinha receio de o magoar ao passá-lo. Mas era importante, porque é mais fácil para lhe dar de comer". Ao ouvir isto, tento averiguar mentalmente a relação benefício/prejuízo de realizar levante do utente para o cadeirão; e se a resposta seria clara há alguns meses, o contexto de pandemia introduz novas variáveis que dificultam o processo de tomada de decisão: "a filha vai estar caraa-cara com ele quando o deitar; e não vai ter quem a ajude, o vizinho agora não entra cá...; mas o risco de aspirar é menor quando o alimentar, a cabeceira da cama só sobe $45^{\circ} .$. e eu estou todo equipado e com máscara FFP2, por isso é seguro eu efetuar a transferência". Após ponderar, decido fazer o levante e proponho: "Se tiver dificuldade, posso passar cá mais logo para o deitar", ao que a filha do utente acede.

Lentamente sento o utente na cama, enquanto sinto o telemóvel a vibrar no bolso. "Espero que não seja nada urgente...". Enquanto faço um compasso de espera com o utente sentado para evitar hipotensão ortostática, maldigo termos apenas dois esfigmomanómetros para 10 profissionais da unidade, situação agravada pela pandemia e consequente necessidade de higienização profunda dos equipamentos entre utentes. Inicio a técnica de levante, com apoio frontal; ao colocar o utente em pé, a viseira fica totalmente espalmada entre nas nossas caras e desloca-se um pouco para o lado, o que me leva a duvidar se não haverá alguma área da minha cara em contacto direto com a cara do utente. O telemóvel volta a vibrar e acentua-se a preocupação de ser algo urgente.

Lentamente rodo o utente em direção ao cadeirão, enquanto sinto os elásticos de punho da bata a subir pelos meus antebraços. "Pronto, lá se foi a proteção de contacto..." penso para mim enquanto me tento distrair da insistência da vibração do telemóvel. Assim que sento o utente, sinto necessidade de sair do domicílio para retirar os EPIs e higienizar as áreas que estiveram em contacto com o utente; tento, com dificuldade, ignorar isso enquanto o utente começa a tossir e o meu instinto me faz dar um passo atrás dado ele não estar com máscara; pondero colocar-lhe a máscara mas recordo-me do desconforto que ele manifestou a última vez que lhe coloquei. Enquanto estruturo mentalmente que intervenções de cinesiterapia respiratória poderei implementar de forma simultaneamente eficaz e segura, um aceso mais forte de tosse mobiliza definitivamente as secreções brônquicas da via aérea, trazendo alívio aos três.

Enquanto vejo crescer a necessidade de sair do domicílio para me higienizar, a filha do utente faz-me algumas perguntas sobre o estado do utente e os cuidados que necessita. Reconhecendo a pertinência das questões, esforço-me por me concentrar e providenciar respostas concretas e corretas. No fim, enquanto me despeço do utente e da filha, tento perceber se me esqueci de alguma coisa, pois regressar ao domicílio implicará, em rigor, a utilização de novos EPIs.

Ao sair do domicílio combino com a filha do utente a gestão do resto do dia, principalmente no que concerne à necessidade de ajuda na transferência do utente para a cama. Cumpro o procedimento e retiro a luva da mão esquerda para a utilizar na abertura da porta do prédio. Ao chegar à viatura tento remover os EPIs corretamente e pela ordem designada, embora esteja pressionado pela necessidade de higienizar a cara e antebraços, bem como pelo telemóvel que insiste em chamar por mim. Por fim, passo SABA nas áreas corporais que assumo terem estado em contacto direto com o utente, seguindo-se a aplicação de desinfetante na porção distal das calças da minha farda. Quando por fim consigo pegar no telemóvel, vejo que é outro utente que me liga, desta feita a concretizar o inesperado: a algália está obstruída.

Sento-me ao volante e roubo 30 segundos ao meu tempo para respirar fundo e tentar perceber se o cansaço que sinto é físico, psicológico, emocional ou uma mistura dos três. E enquanto rodo a chave na ignição digo para mim mesmo, num desabafo para uma plateia solitária: "um já está, só faltam quatro...". 